\title{
Consideration of the nonlinear behavior of environmental material and a three-dimensional internal heat sources in mathematical modeling of heat conduction
}

\author{
Zhuravchak L. M. ${ }^{1}$, Kruk O. S. ${ }^{2}$ \\ ${ }^{1}$ Carpathian Branch of Subbotin Institute \\ of Geophysics of National Academy of Sciences \\ 3-b Naukova str.,79060, Lviv, Ukraine \\ ${ }^{2}$ Lviv Polytechnic National University \\ 12 S. Bandera str., 79013, Lviv, Ukraine
}

(Received 20 March 2015)

\begin{abstract}
A numerical-analytical method of determining the heat field in a finite solid with taking into account the dependence of the coefficients of heat conductivity and of heat release on the temperature and the intensity of internal heat sources is suggested. The effectiveness of the combination of indirect methods of boundary and near-boundary elements with Kirchhoff transformation for partial linearization of nonlinear 3D problems of heat conduction, by which the process is modelled, is substantiated.
\end{abstract}

Keywords: temperature field, materials with temperature-dependent characteristics, the indirect boundary element method, the indirect near-boundary element method, the Kirchhoff transformation, internal heat source

2000 MSC: $65 \mathrm{~N} 38,93 \mathrm{~B} 18,80 \mathrm{~A} 10$

UDC: $517.958: 536.12$

\section{Introduction}

Modeling and optimization of thermal processes are essential in a variety of industries and technology particularly in instrument-making and mechanical engineering, in the design of microelectronic devices, cover constructions and fireproof equipment. As a rule thermal properties of materials depend on temperature under the influence internal heat sources and external thermal factors.

The linear mathematical models based on the assumption of piecewise constant thermal characteristics of materials which depend on the coordinates are not always adequately describing the actual processes. The more reliable models that take into account the effect of temperature on the coefficients of thermal diffusivity of material components, which leads to nonlinear problems. Mainly for their solution, we use analytical methods and numerical methods tend to canonical form [1-5]. One approach we use in finding solutions to these problems is the selection operator that describes the effect of nonlinearity. We apply to it the iterative method using sampling area nonlinearity [6, 7]. Another way, more effective way of solving the stationary and non-stationary problems in the case of simple non-linearity (when the thermal diffusivity was temperature dependent and can be considered sustainable) is to use Kirchhoff transformation that reduces non-linear to linear equations $[1-4,8,9]$.

\section{The partial linearization of the problem using Kirchhoff transformation}

We consider a plate homogeneous region $\Omega \subset \mathbb{R}^{3}$ with a simple closed edge $\Gamma$. The thermal conductivity $\lambda(\theta)$ of material object and a heat transfer coefficient with its limits $\alpha(\theta)$ are continuous functions of the unknown temperature $\theta(x)[1,2]$ :

$$
\lambda(\theta)=\lambda_{0}\left(1+\lambda_{0}(\theta) S_{+}\left(\theta-\theta_{\lambda}\right) \chi_{\theta}\right), \quad \alpha(\theta)=\alpha_{0}\left(1+\alpha_{0}(\theta) S_{+}\left(\theta-\theta_{\lambda}\right) \chi_{\theta}\right),
$$


where $\chi_{\theta}$ is a characteristic function of region $\Omega_{\theta}, \theta>\min \left(\theta_{\lambda}, \theta_{\alpha}\right), S_{+}(z)=1(z>0), S_{+}(z)=0$ $(z \leqslant 0), x=\left(x_{1}, x_{2}, x_{3}\right)$. The behavior of the temperature field, the heat flow and convective heat exchange with the environment, the temperature of which is $\theta_{c}(x)$ are known on the part $\partial \Omega^{s} \subset \Gamma(s=$ $=1,2,3), \bigcup_{s=1}^{3} \partial \Omega^{s}=\Gamma$. Inside area $\Omega$ heat source fo intensity $\psi(x)$ exists.

To determine the stationary temperature field in $\Omega$ we have a non-linear equation [2]

$$
\sum_{j=1}^{3} \frac{\partial}{\partial x_{j}}\left(\lambda(\theta) \frac{\partial \theta(x)}{\partial x_{j}}\right)=-\psi(x) \chi_{\psi}, \quad x \in \Omega \subset \mathbb{R}^{3},
$$

boundary conditions of the first, second and third kind.

$$
\begin{aligned}
& \theta(x)=\theta_{\Gamma}(x), x \in \partial \Omega^{1}, \quad-\lambda(\theta) \frac{\partial \theta(x)}{\partial n(x)}=q_{\Gamma}(x), \quad x \in \partial \Omega^{2}, \\
& \alpha(\theta) \theta(x)-\lambda(\theta) \frac{\partial \theta(x)}{\partial n(x)}=\alpha(\theta) \theta_{c}(x), \quad x \in \partial \Omega^{3} .
\end{aligned}
$$

$n(x)=\left(n_{1}(x), n_{2}(x), n_{3}(x)\right)$ is outdoor uniquely defined normal to $\Gamma, \psi(x)$ is intensity sources in $\Omega_{\psi} \subset \Omega ; \chi_{\psi}$ is the area characteristic function $\Omega_{\psi}, \chi_{\psi}=1, x \in \chi_{\psi}, \chi_{\psi}=0, x \notin \chi_{\psi}$.

A well-known direct and inverse Kirchhoff transformation takes place:

$$
\vartheta(x)=K\left(\theta^{(m)}(x)\right)=\frac{1}{\lambda_{0}} \int_{\theta^{(0)}}^{\theta(x)} \lambda(\zeta) \mathrm{d} \zeta,
$$

and inverse Kirchhoff transformation takes place

$$
K^{-1}(\vartheta(x))=\theta(x)
$$

to find $\vartheta(x)$ we obtain the partially linearized problem:

$$
\begin{aligned}
\Delta \vartheta(x) & =-\psi(x) \chi_{\psi}, \quad x \in \Omega, \\
\vartheta(x) & =K\left(\theta_{\Gamma}(x)\right), x \in \partial \Omega^{1}, \quad-\frac{\partial \vartheta(x)}{\partial n(x)}=q_{\Gamma}(x), x \in \partial \Omega^{2}, \\
-\frac{\partial \vartheta(x)}{\partial n(x)} & +\alpha\left(K^{-1}(\vartheta)\right) K^{-1}(\vartheta)=\alpha\left(K^{-1}(\vartheta)\right) \theta_{c}(x), x \in \partial \Omega^{3},
\end{aligned}
$$

where $\Delta=\sum_{i=1}^{3} \frac{\partial^{2}}{\partial x_{i}^{2}}$ is the Laplace operator, $\theta^{(0)}$ is the characteristic temperature.

We see that the Kirchhoff transformation linearizes the original equation (2) and boundary conditions of the second kind (3), boundary conditions of the first kind are linear, and the boundary condition of the third kind (3) remain nonlinear.

\section{Construction of integral solutions representations of the linear equation and discrete- continuous model}

We use indirect boundary and near-boundary elements methods $[4,6]$. We enter at the border $\Gamma$ of area $\Omega$ and in external to it near-boundary zone $G=B \backslash \Omega$ of thickness $h\left(\Omega \subset B \subset \mathbb{R}^{3}, \Gamma \cap \partial B=\oslash\right.$, $\partial B$ is limit of area $B$ ) fictitious heat source unknown intensity $\varphi^{(\Gamma)}(x), \varphi^{(G)}(x)$. 
We describe an unknown function by equation

$$
\Delta \vartheta^{(\gamma)}(x)=-\varphi^{(\gamma)}(x) \chi_{\gamma}-\psi(x), \quad x \in \mathbb{R}^{3}, \gamma \in\{\Gamma, G\}
$$

where $\chi_{\gamma}(x)$ is characteristic function $\gamma$, that is $\chi_{\gamma}(x)=1(x \in \gamma), \chi_{\gamma}(x)=0(x \notin \gamma)$.

Then Kirchhoff integral image variable as the solution of equations (7) and its normal derivative are represented as following:

$$
\vartheta^{(\gamma)}(x)=F^{\gamma}(x, U)+F_{\psi}(x, U), \quad \frac{\partial \vartheta^{(\gamma)}(x)}{\partial n(x)}=F^{\gamma}(x, Q),
$$

where $F^{\gamma}(x, \Phi)=\int_{\gamma} \Phi(x, \xi) \varphi^{(\gamma)}(\xi) \mathrm{d} \gamma(\xi), F_{\psi}(x, \Phi)=\int_{\Omega_{\psi}} \Phi(x, \xi) \psi(\xi) \mathrm{d} \Omega_{\psi}(\xi), U(x, \xi)$ is fundamental solution of the Laplace operator, which exactly satisfies the equation (5) in $\Omega, \xi=\left(\xi_{1}, \xi_{2}, \xi_{3}\right) \in \mathbb{R}^{3}$,

$$
Q(x, \xi)=-\sum_{j=1}^{3} Q_{j}(x, \xi) n_{j}(x), \quad Q_{j}(x, \xi)=\frac{\partial U(x, \xi)}{\partial x_{j}} .
$$

We reinforce $x$ in (8) from the middle $\Omega$ to $\Gamma$ to meet the conditions (3), obtain boundary integral equation (BIE), which links unknown $\varphi^{(\gamma)}(\xi)$ with functions specified on $\Gamma$ :

$$
\begin{gathered}
F^{\gamma}(x, U)=K\left(\theta_{\Gamma}(x)\right)-F_{\psi}(x, U), x \in \partial \Omega^{1} \\
F^{\gamma}(x, Q)=q_{\Gamma}(x)-F_{\psi}(x, Q), x \in \partial \Omega^{2}, \\
\alpha\left(K^{-1}\left(F^{\gamma}(x, U)+F_{\psi}(x, U)\right) K^{-1}\left(F^{\gamma}(x, U)+F_{\psi}(x, U)\right)+F^{\gamma}(x, Q)\right)= \\
=\alpha\left(K^{-1}\left(F^{\gamma}(x, U)+F_{\psi}(x, U)\right) \theta_{c}(x)-F_{\psi}(x, Q)\right), \quad x \in \partial \Omega^{3},
\end{gathered}
$$

To find the solutions of the system (9) we implemented spatial discretization. We discretize the region $G$ and limit $\Gamma$ on near-boundary elements $G_{\nu}$ and boundary elements $\Gamma_{\nu}(\nu=1, \ldots, V)$ and we approximate unknown functions $\varphi^{(G)}(\xi), \varphi^{(\Gamma)}(\xi)$ by constants $d_{\nu}^{G}, d_{\nu}^{\Gamma}$. However mes $G_{\nu}=l, \bigcup_{\nu=1}^{V} G_{\nu}=$ $=G, \bigcup_{\nu=1}^{V_{1}}\left(\partial G_{\nu} \cap \Gamma\right)=\partial \Omega^{1}, \bigcup_{\nu=V_{1}+1}^{V_{2}}\left(\partial G_{\nu} \cap \Gamma\right)=\partial \Omega^{2}, \underset{\nu=V_{2}+1}{V}\left(\partial G_{\nu} \cap \Gamma\right)=\partial \Omega^{3}, G_{\nu} \cap G_{\omega}=\oslash, \Gamma_{\nu}^{k} \cap \Gamma_{\omega}^{k}=\oslash$, $\nu \neq \omega, \underset{\nu=1}{U} \Gamma_{\nu}=\Gamma, \bigcup_{\nu=1}^{V_{1}} \Gamma_{\nu}=\partial \Omega^{1}, \bigcup_{\nu=V_{1}+1}^{V_{2}} \Gamma_{\nu}=\partial \Omega^{2}, \bigcup_{\nu=V_{2}+1}^{V_{1}} \Gamma_{\nu}=\partial \Omega^{3}$. It is clear that each boundary element should fully belong to one of the sites $\partial \Omega^{s}(s=1,2,3)$, which are sampled according to elements $V_{1}, K_{2}, K_{3}$, however elements numbering began with the first section and continues to the next $V_{2}=V_{1}+K_{2}, V=V_{1}+K_{2}+K_{3}$.

After spatial discretization we obtain a system of nonlinear algebraic equations (SNLAE).

$$
\begin{aligned}
\mathrm{f}(\mathrm{d})= & 0, \quad \mathrm{~d}=\left(d_{1}^{\gamma}, \ldots, d_{V}^{\gamma}\right), \quad \mathrm{f}(\mathrm{d})=\left(f_{1}(\mathrm{~d}), f_{2}(\mathrm{~d}), \ldots, f_{V}(\mathrm{~d})\right)^{T}, \\
f_{w}(\mathrm{~d})= & \sum_{\nu=1}^{V} A_{\nu}^{\gamma}\left(x^{w}, U\right) d_{v}^{\gamma}-\mathrm{K}\left(\theta_{\Gamma}\left(x^{\omega}\right)\right)+\mathrm{F}_{\psi}\left(x^{\omega}, U\right), x^{\omega} \in \partial \Omega^{1}, \omega=1, \ldots, V_{1}, \\
f_{w}(\mathrm{~d})= & \sum_{\nu=1}^{V} A_{\nu}^{\gamma}\left(x^{w}, Q\right) d_{v}^{\gamma}-q_{\Gamma}\left(x^{\omega}\right)+\mathrm{F}_{\psi}\left(x^{\omega}, Q\right), x^{\omega} \in \partial \Omega^{2}, \omega=V_{1}+1, \ldots, V_{2}, \\
f_{w}(\mathrm{~d})= & \alpha\left(\mathrm{K}\left(\sum_{\nu=1}^{V} A_{\nu}^{\gamma}\left(x^{w}, U\right) d_{v}^{\gamma}+\mathrm{F}_{\psi}\left(x^{\omega}, U\right)\right) \mathrm{K}^{-1}\left(\sum_{\nu=1}^{V} A_{\nu}^{\gamma}\left(x^{w}, U\right) d_{v}^{\gamma}+\mathrm{F}_{\psi}\left(x^{\omega}, U\right)\right)+\sum_{\nu=1}^{V} A_{\nu}^{\gamma}\left(x^{w}, Q\right) d_{v}^{\gamma}\right)- \\
& -\alpha\left(\mathrm{K}^{-1}\left(\sum_{\nu=1}^{V} A_{\nu}^{\gamma}\left(x^{w}, U\right) d_{v}^{\gamma}+\mathrm{F}_{\psi}\left(x^{\omega}, U\right)\right) \theta_{c}\left(x^{\omega}\right)+\mathrm{F}_{\psi}\left(x^{\omega}, Q\right)\right), x^{\omega} \in \partial \Omega^{3}, \omega=V_{2}+1, \ldots, V,
\end{aligned}
$$


$x^{\omega} \in \Gamma_{\omega},(\omega=1, \ldots, V)$ is a point of collocation, selected as the "center of mass" of boundary element. For solving SNLAE (10) we use a modified Newton method [7], the essence of this modification is that at every step of the method is not necessary to calculate the matrix inverse to the Jacobi matrix, in the corresponding point. Instead we use one and the same inverse matrix calculated at the start point. As an initial approximation we solve the problem with boundary conditions of the first kind, we get the SLAE on the first step [5]. The SLAE we solved using Gauss-Newton method.

We obtained solutions of SNLAE $\mathrm{d}^{(\gamma K)}$, and we using it of the Kirchhoff variable and derivative by normal:

$$
\vartheta^{(\gamma)}(x)=\sum_{\nu=1}^{V} A_{\nu}^{\gamma}(x, U) d_{\nu}^{\gamma K}+F_{\psi}(x, U), \quad-\frac{\partial \vartheta^{(\gamma)}(x)}{\partial n(x)}=\sum_{\nu=1}^{V} A_{\nu}^{\gamma}(x, Q) d_{\nu}^{\gamma K}+F_{\psi}(x, Q),
$$

where $A_{\nu}^{\gamma}(x, \Phi)=\int_{\gamma_{\nu}} \Phi(x, \xi) \mathrm{d} \gamma_{\nu}(\xi)$. The integrals $A_{\nu}^{G}(x, U), A_{\nu}^{G}(x, Q), A_{\nu}^{\Gamma}(x, U)$, at $\xi=x$ containing, and $A_{\nu}^{\gamma}(x, Q)$ we calculated in Cauchy terms.

In next step, we use the inverse Kirchhoff transformation (4) and (11) to find unknown temperature and heat flux by the formulas:

$$
\theta^{(\gamma)}(x)=K^{-1}\left(\vartheta^{(\gamma)}(x)\right), \quad-\lambda\left(\theta^{(\gamma)}\right) \frac{\partial \theta^{(\gamma)}(x)}{\partial n(x)}=-\frac{\partial \vartheta^{(\gamma)}(x)}{\partial n(x)}
$$

\section{Numerical experiments}

For numerical experiments we reviewed an isotropic homogeneous parallelepiped in Cartesian coordinates $x_{1}, x_{2}, x_{3}$ which occupies an area

$$
\Omega=\left\{\left(x_{1}, x_{2}, x_{3}\right): a_{1}<x_{1}<a_{2}, b_{1}<x_{2}<b_{2}, c_{1}<x_{3}<c_{2}\right\}
$$

with limit $\Gamma=\bigcup_{j=1}^{6} \Gamma^{(j)}$, where $\Gamma^{(1)}, \Gamma^{(2)}$ is a left border, right border, $\Gamma^{(3)}, \Gamma^{(4)}$ is a bottom border, top border, $\Gamma^{(5)}, \Gamma^{(6)}$ is a back border and front border of parallelepiped, where $a_{1}=-1, a_{2}=1, b_{1}=-1$, $b_{2}=1, c_{1}=-1, c_{2}=1, h=0.01$.

We used the indirect method of near-boundary elements for the distribution of the thermal field with an exponential dependence a thermal conductivity from temperature $\lambda(\theta)=\lambda_{0} \exp \left(\beta_{\lambda} \frac{\theta-\theta_{\exp }^{(0)}}{\theta_{\exp }^{(0)}}\right)$, at $\lambda_{0}=1, \beta_{\lambda}=0.01, \theta_{\exp }^{(0)}=100$ for the problem of the third kind (3)

$$
\begin{aligned}
\theta_{\Gamma}(x) & =100+x_{3}, \theta_{c}(x)=x^{2} / 4+10.75, x_{3}=1, \theta_{c}(x)=x^{2} / 4+8.75, x_{3}=-1, \\
\alpha(\theta) & =1, x \in \Gamma^{(i)}, i=\overline{1,6},
\end{aligned}
$$

without inner sources. The results are shown in fig. 1.

We assessed the effect power of inner sources. In the first we evaluated the effect of inner sources in the plates form

$$
\Omega_{\psi_{2}}=\left\{\left(x_{1}, x_{2}, x_{3}\right):-d \leqslant x_{1} \leqslant d, x_{2}=0.25,-d \leqslant x_{3} \leqslant d\right\}
$$

with intensity

$$
\widetilde{\psi}(x)=\psi_{g}\left(1+\cos \frac{\pi x_{1}}{d}\right)\left(1+\cos \frac{\pi x_{2}}{d}\right),
$$

where $d=0.5$. The results are shown in fig. 2 . 


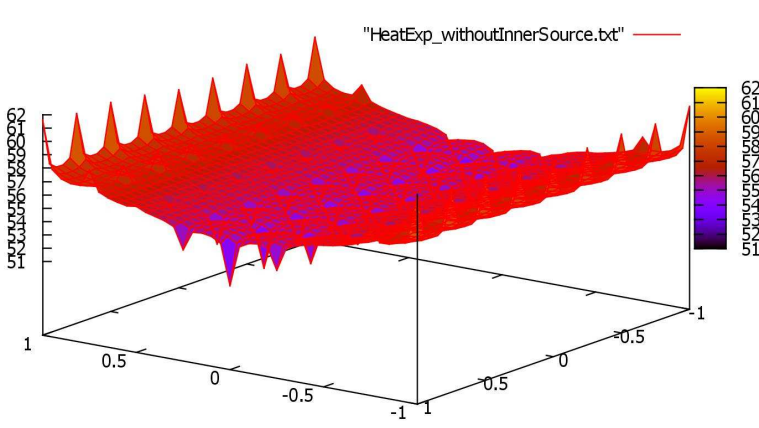

(a)

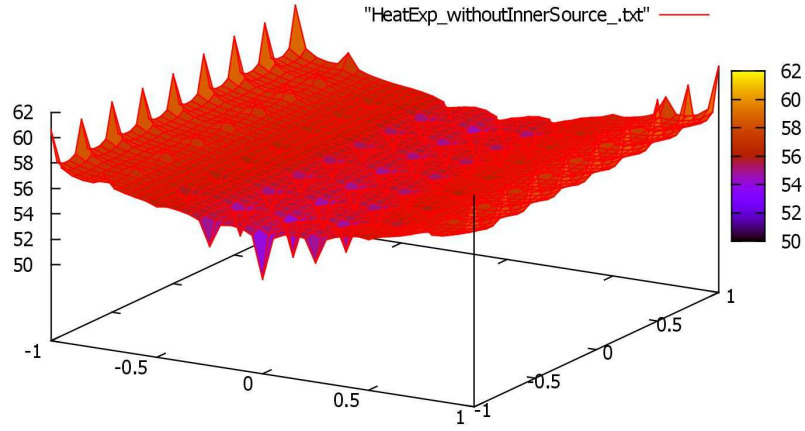

(b)

Fig. 1. The distribution of the temperature field inside the object on the plane $x_{2}=0.5$ (a) and $x_{2}=-0.5$ (b) for $V=36$ with an exponential dependence without inner sources.

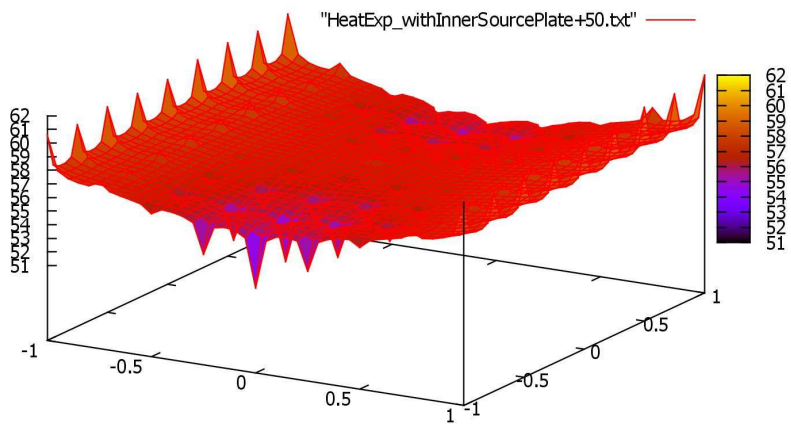

(a)

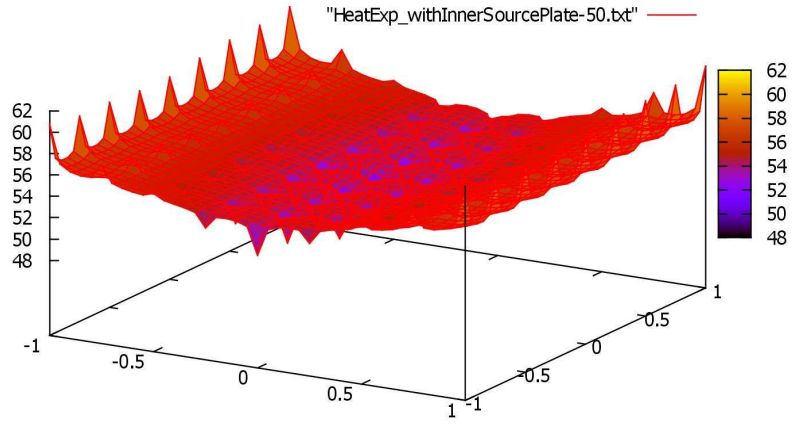

(b)

Fig. 2. The distribution of the temperature field inside the object on the plane $x_{2}=0.5$ for $V=36$ with an exponential dependence for a given inner heat source in the plates form with heating $\left(\psi_{g}=50\right)(\mathrm{a})$ and with cooling $\left(\psi_{g}=-50\right)(\mathrm{b})$.

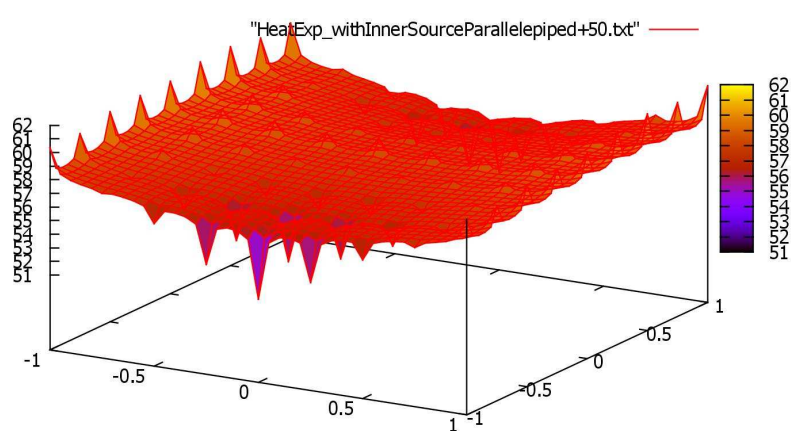

(a)

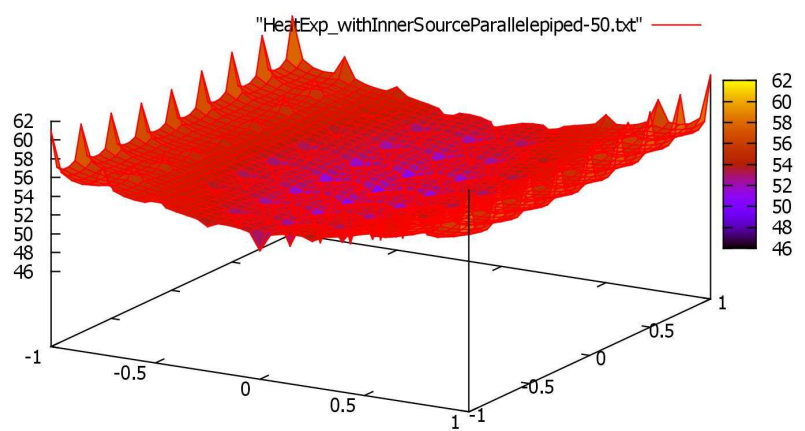

(b)

Fig. 3. The distribution of the temperature field inside the object on the plane $x_{2}=0.5$ for $V=36$ with an exponential dependence for a given inner heat source in the parallelepiped form with heating $\left(\psi_{g}=50\right)($ a) and with cooling $\left(\psi_{g}=-50\right)(\mathrm{b})$. 
In the second we evaluated the effect of inner sources in the 3D form

$$
\Omega_{\psi_{3}}=\left\{\left(x_{1}, x_{2}, x_{3}\right):-d_{1} \leqslant x_{1} \leqslant d_{1},-d_{2} \leqslant x_{2} \leqslant d_{2},-d_{3} \leqslant x_{3} \leqslant d_{3}\right\}
$$

with intensity

$$
\widetilde{\psi}(x)=\psi_{g}\left(1+\cos \frac{\pi x_{1}}{d_{1}}\right)\left(1+\cos \frac{\pi x_{2}}{d_{2}}\right)\left(1+\cos \frac{\pi x_{3}}{d_{3}}\right),
$$

where $d_{1}=0.25, d_{2}=d_{3}=0.75$. The results are shown in fig. 3 .

During numerous experiments, when we took solution of the linearized problem for the initial approximation, then we have not always received convergent iterative process. So we chose for the initial approximation the solution of linearized problem with boundary conditions of the first kind. The error $e=0.001$ was achieved for the 8-10 steps. All numerical results we have got from using an indirect near-boundary elements method (INBEM), because during the Kirchhoff conversion we got higher accuracy than indirect boundary element method (IBEM). As you can see, when the internal heating source $\left(\psi_{g}=50\right)$ the temperature increases in parallelepiped, and on cooling source $\left(\psi_{g}=-50\right)$ the temperature decreases.

\section{Conclusions}

We have developed numerical and analytical approach for mathematical modeling of three-dimensional stationary thermal field, which is based on INBEM, Kirchhoff transformation and a modified Newton's method. This approach makes it possible to determine the temperature and heat flow in the heatsensitive environment considering its thermal characteristics depending on the unknown temperature. We confirmed the efficiency of INBEM for solving nonlinear system of boundary integral equations, which describe the heat conduction process, and allows us to weaken the singularity of the equation compared to IBEM. Also INBEM simplifies the construction of discrete-continuum models, and significantly improves accuracy when calculating the desired values near the body and on the verge of body. In INBEM all integrals are considered in the Riemann terms (in IBEM calculation of the heat flux requires the finding integrals in the Cauchy terms). This provided diagonal advantage of SNLAE elements. The near-boundary region with additional parameter smoothed effect of inner sources, and, therefore achieved higher than IBEM accuracy using the same number of boundary elements and the same degree of approximation of unknown intensity. Difference for INBEM method for two and three dimensional heat conduction problems are mainly seen in form of near-boundary elements and fundamental solution of the Laplace equation. Modular construction principle unified software development part and in the future will allow expand the range of research studies on piecewise homogeneous bodies.

[1] Pidstryhach Y.S., Lomakin V.A., Kolyano Y. M. The bodies thermoelasticity in homogeneous structure. M.: Nauka, 368 (1984).

[2] Kolyano Y. M. The methods of heat conduction and thermoelasticity inhomogeneous body. K.: Naukova dumka, 280 (1992).

[3] Kushnir R. M., Popovich V.S. Simulation and optimization of heterogeneous termomehanics conductive bodies. Under gen. vers. Burak Ya. Y., Kushnir R. M. The thermoelasticity thermosensitive bodies Lviv, SPOLOM 3, 412 (2009).

[4] Kushnir R., Protsiuk B. A Method of the Green's Functions for Quasistatic Thermoelasticity Problems in Layered Thermosensitive Bodies under Complex Heat Exchange. Operator Theory Advances and Applications 191, 143-154 (2009).

[5] Fedasyuk D., $\dot{V}$. The methods and tools for thermal design of microelectronic devices L. Pub. DU "Lviv Polytechnic", 228 (1999).

Mathematical Modeling and Computing, Vol. 2, No. 1, pp. 107-113 (2015) 
[6] Zhuravchak L. M., Grytsko Y. G. Near-boundary element technique in applied problems of mathematical physics. Carpathian Branch of Subbotin Institute of Geophysics, NAS of Ukraine, Lviv, Ukraine, 220 (1996).

[7] Zhuravchak L. M. Solution of spatial nonstationary heat conduction problem for zonal-homogeneous thermosensitive body. Mathematical methods and physical-mechanical fields. 45, 137-142 (2002).

[8] Zhuravchak L. M. Solution of spatial thermal conductivity problem for zonal-homogeneous thermosensitive body with arbitrary form. Reports of National Academy of Sciences of Ukraine. 8, 37-41 (2002).

[9] Zhuravchak L. M. Zabrodska N. V. Nonstationary thermal fields in inhomogeneous materials with nonlinear behaviour of the components. Materials Science. 46-1, 33-41 (2010).

[10] Brebbia C. A., Telles J. C. F. Wrobel L. C. Boundary element methods. Theory and Application in Engineering, Springer-Verlag (1984).

[11] Zhuravchak L. M. Kruk O. S. Mathematical modeling of thermal field distribution in the parallelepiped with the severe heat on its borders and internal sources. Visnyk NU "Lviv Polytechnic" Computer Science and Information Technology. 771, 291-302 (2013).

\title{
Урахування нелінійної поведінки матеріалу середовища та об'ємних внутрішніх джерел при математичному моделюванні процесу теплопровідності
}

\author{
Журавчак Л. М. ${ }^{1}$, Крук О. С. ${ }^{2}$ \\ ${ }^{1}$ Карпатське відділення Інституту геофізики ім. С. І. Субботіна НАН Украӥни \\ вул. Наукова, 3-Б, 79060, Лъвів, Украӥна \\ ${ }^{2}$ Начіональний університет «Львівсъка політехніка» \\ вул. С. Бандери, 12, 79013, Лъвів, Україна
}

\begin{abstract}
Запропоновано чисельно-аналітичну методику знаходження теплового поля в обмеженому тілі з урахуванням залежності коефіцієнтів теплопровідності та тепловіддачі від температури та інтенсивності внутрішніх джерел. Обгрунтовано ефективність поєднання непрямих методів граничних та приграничних елементів з перетворенням Кірхгофа для часткової лінеаризації нелінійних тривимірних задач теплопровідності, якими змодельовано вказаний процес. 3 використанням інтегральних зображень для змінної Кірхгофа побудовано дискретно-континуальну модель задачі з мішаними граничними умовами першого, другого та третього роду. Здійснено низку обчислювальних експериментів для експоненційної залежності коефіцієнта теплопровідності від температури, оцінено вплив плоских та об'ємних джерел на розподіл температурного поля в паралелепіпеді.
\end{abstract}

Ключові слова: матеріали із залежними від температури характеристиками, теплове поле, непрямий метод граничних елементів, непрямий метод пригранииних елементів, перетворення Кірхгофа, внутрішні джерела

2000 MSC: $65 \mathrm{~N} 38,93 \mathrm{~B} 18,80 \mathrm{~A} 10$

Удк: 517.958:536.12

Mathematical Modeling and Computing, Vol.2, No.1, pp.107-113 (2015) 